\title{
Genetic Analysis of African Swine Fever Virus From the 2018 Outbreak in South-Eastern Burundi
}

\section{OPEN ACCESS}

Edited by:

Maureen T. Long,

University of Florida, United States

Reviewed by:

Alex Malogolovkin,

University of London, United Kingdom

Dongbo Sun,

Heilongjiang Bayi Agricultural

University, China

Edgar Simulundu,

University of Zambia, Zambia

*Correspondence:

Gerald Misinzo

gerald.misinzo@sacids.org

Specialty section:

This article was submitted to

Veterinary Infectious Diseases,

a section of the journal

Frontiers in Veterinary Science

Received: 30 June 2020

Accepted: 01 October 2020

Published: 05 November 2020

Citation:

Hakizimana JN, Nyabongo L, Ntirandekura JB, Yona $C$

Ntakirutimana $D$, Kamana $\mathrm{O}$, Nauwynck H and Misinzo G (2020)

Genetic Analysis of African Swine

Fever Virus From the 2018 Outbreak in South-Eastern Burundi.

Front. Vet. Sci. 7:578474.

doi: 10.3389/fvets.2020.578474

\begin{abstract}
Jean N. Hakizimana ${ }^{1,2}$, Lionel Nyabongo ${ }^{3}$, Jean B. Ntirandekura ${ }^{4}$, Clara Yona ${ }^{1,5}$, Désiré Ntakirutimana ${ }^{3}$, Olivier Kamana ${ }^{6,7}$, Hans Nauwynck ${ }^{8}$ and Gerald Misinzo ${ }^{1,2 *}$

1 SACIDS Africa Centre of Excellence for Infectious Diseases, SACIDS Foundation for One Health, Sokoine University of Agriculture, Morogoro, Tanzania, ${ }^{2}$ Department of Veterinary Microbiology, Parasitology and Biotechnology, College of Veterinary Medicine and Biomedical Sciences, Sokoine University of Agriculture, Morogoro, Tanzania, ${ }^{3}$ National Veterinary Laboratory of Burundi, Bujumbura, Burundi, ${ }^{4}$ Department of Animal Health and Productions, University of Burundi, Bujumbura, Burundi, ${ }^{5}$ Department of Biosciences, Solomon Mahlangu College of Science and Education, Sokoine University of Agriculture, Morogoro, Tanzania, ${ }^{6}$ Department of Food Science and Technology, College of Agriculture, Animal Sciences and Veterinary Medicine, University of Rwanda, Busogo, Rwanda, ${ }^{7}$ Department of Applied Research and Development and Foresight Incubation, National Industrial Research and Development Agency, Kigali, Rwanda, ${ }^{8}$ Laboratory of Virology, Faculty of Veterinary Medicine, Ghent University, Merelbeke, Belgium
\end{abstract}

African swine fever (ASF) is a contagious viral disease that causes high mortality, approaching $100 \%$, in domestic pigs and wild boars. The disease has neither a cure nor a vaccine, and it is caused by an ASF virus (ASFV), the only member of the family Asfarviridae, genus Asfivirus, and the only known DNA arbovirus. Twenty-four genotypes of ASFV have been described to date, and all of them have been described in Africa. ASF is endemic in Burundi, and several outbreaks have been reported in the country; the disease continues to economically impact on small-scale farmers. This study aimed at genetic characterization of ASFV that caused an ASF outbreak in the Rutana region, Burundi, in the year 2018. Tissue samples from domestic pigs that died as a result of a severe hemorrhagic disease were collected in order to confirm the disease using polymerase chain reaction (PCR) and to conduct partial genome sequencing. Nucleotide sequences were obtained for the B646L (p72) gene, the intergenic fragment between the $173 R$ and $1329 \mathrm{~L}$ genes, and the central variable region (CVR) of the $B 602 L$ gene. Phylogenetic analysis of the Burundian 2018 ASFV grouped the virus within B646L (p72) genotype $X$ and clustered together with those reported during the 1984 and 1990 outbreaks in Burundi with high nucleotide identity to some ASFV strains previously reported in neighboring East African countries, indicating a regional distribution of this ASFV genotype. Analysis of the intergenic fragment between I73R and $1329 \mathrm{~L}$ genes showed that the Burundian 2018 ASFV described in this study lacked a 32-base pair (bp) fragment present in the reference genotype $X$ strain, Kenya 1950. In addition, the strain described in this study had the signature AAABNAABA at the CVR (B602L) gene and showed $100 \%$ amino acid sequence identity to viruses responsible for recent ASF outbreaks in the region. The virus described in this study showed high genetic similarities with ASFV strains previously described in domestic pigs, wild suids, and soft ticks in East African countries, indicating a possible common wild source and continuous circulation in domestic pigs in the region.

Keywords: African swine fever, Asfarviridae, Burundi, domestic pigs, genotyping 


\section{INTRODUCTION}

African swine fever (ASF) is a contagious and fatal viral disease of domestic pigs and wild boar $(1,2)$. It is caused by the ASF virus (ASFV), the only member of the family Asfarviridae, genus Asfivirus (3), and the only known DNA arbovirus. Twenty-four (I to XXIV) genotypes of ASFV have been described to date based on nucleotide sequencing of the B646L gene encoding for the p72 protein (4-6), and all of them have been described in Africa (2). Depending on the virus strain, the ASFV genomes vary in length from about 170 to 193 kilobase pairs (Kbp) and contain between 151 and 167 open reading frames with a conserved central region and variable termini (7). Depending on the ASFV strain, morbidities and mortalities can reach $100 \%$, making ASF the most serious constraint to domestic pig production, food and nutritional security, and livelihood of small-scale farmers in Africa (8). ASF has neither a cure nor a vaccine, and its effective control relies on quarantine, stamping out, and strict biosecurity measures $(9,10)$. ASF is endemic in many African countries south of the Sahara and in Sardinia (Italy), and in recent years, it has spread beyond its traditional geographical boundaries to the Caucasus region, the European Union, and Asia (11-14). The recent spread to China, which is the major pork-producing country, is threatening global food security (15, 16). The epidemiology of ASF is complex, transmission is direct and vector-borne, and the disease has well-recognized sylvatic and domestic cycles (17). In Eastern and Southern Africa, ASFV is maintained in a sylvatic cycle between warthogs (Phacochoerus africanus) and soft argasid ticks of the Ornithodoros moubata complex (18). Warthogs and bushpigs (Potamochoerus spp.) are the natural hosts of ASFV that are persistently infected with no obvious clinical disease, and soft ticks of the genus Ornithodoros are vectors for transmission of ASFV from the sylvatic to the domestic cycle (19). Wild natural hosts of ASFV have been reported to be present in the Kibira and Ruvubu National Parks of Burundi (20), but their role in the maintenance and transmission of the virus in the country is not known. In the domestic cycle, two transmission patterns are recognized, namely, a tick-topig cycle that involves soft ticks inhabiting pig shelters and an exclusively pig-to-pig cycle. Once introduced into domestic pig

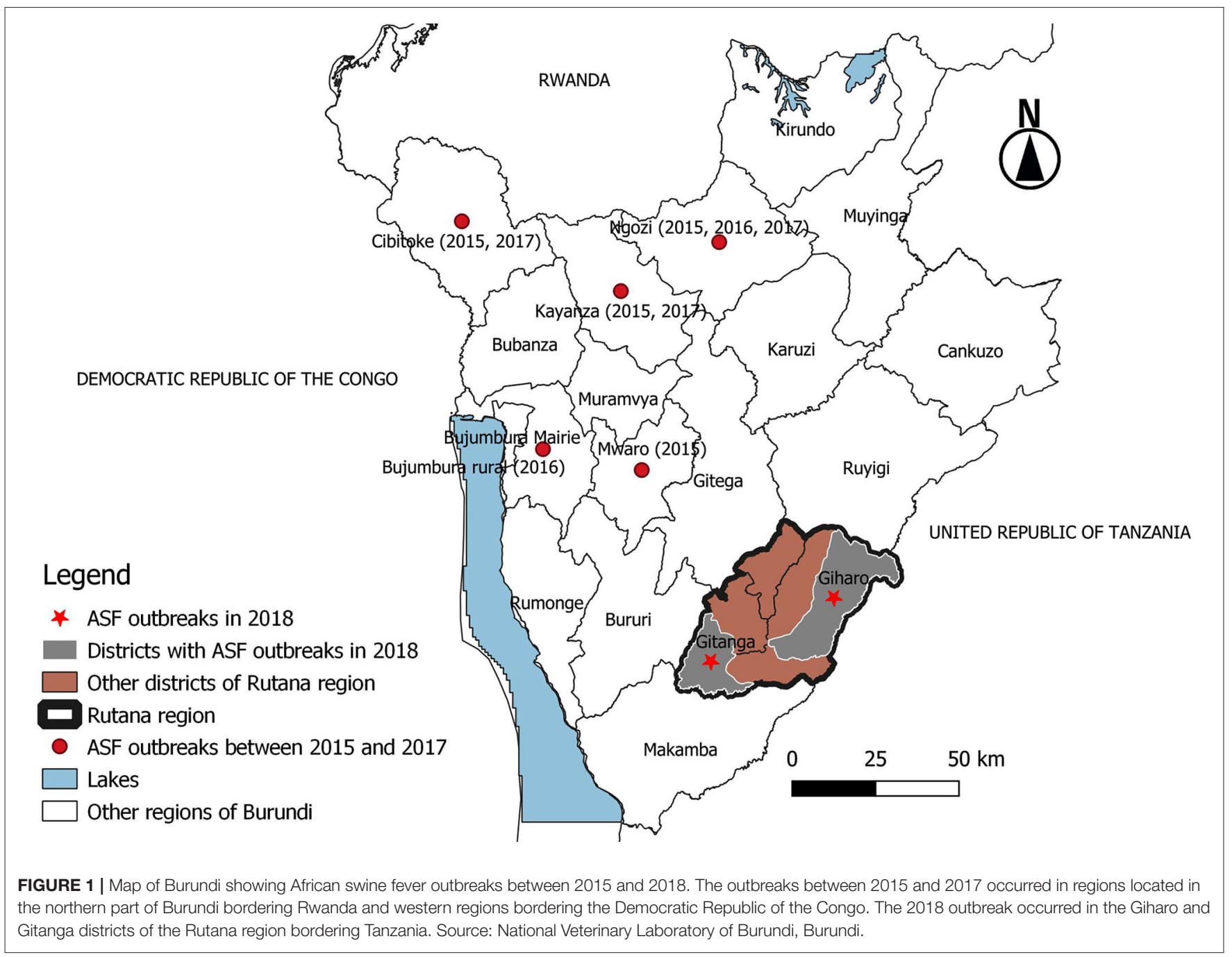


populations, the virus can be transmitted between domestic pigs mainly by ingestion of contaminated feeds and direct contact between infected and susceptible pigs (21).

In Eastern and Southern Africa, some ASFV genotypes are country specific, while others have a transboundary distribution (22). In Burundi, strains of ASFV described from the outbreaks of 1984 and 1990 belong to B646L (p72) genotype X (21). Genotype $\mathrm{X}$ is one of the predominant genotypes in East African countries including Tanzania, Kenya, and Uganda (2325). Despite the regular ASF outbreak reports in domestic pigs in Burundi, molecular characterization of the causative viruses has been limited. For instance, the currently available ASFV strains genetically characterized from Burundi were collected more than two decades ago. In August 2018, an outbreak of a hemorrhagic and fatal disease affecting domestic pigs suspected to be ASF occurred in the Rutana region in South-Eastern Burundi. This study describes the confirmation and molecular characterization of the 2018 outbreak of ASFV in South-Eastern Burundi based on partial amplification and nucleotide sequencing of the B646L (p72) gene, the tandem repeat sequence (TRS) located between the $I 73 R$ and $I 329 L$ genes, and the central variable region (CVR) of the $B 602 L$ gene.

\section{MATERIALS AND METHODS}

\section{Study Area, Sampling, and Sample Processing}

An outbreak of a hemorrhagic disease associated with high mortalities in domestic pigs occurred in South-Eastern Burundi

TABLE 1 African swine fever virus (ASFV) isolates from Eastern and Southern Africa used for the construction of phylogenetic tree based on partial B646L (p72) gene nucleotide sequences.

\begin{tabular}{|c|c|c|c|c|c|c|c|}
\hline Isolate & Host species & Year of isolation & Location & Country & Accession number & p72 genotype & Reference \\
\hline $\mathrm{DRC} / 35 / 10 / 5$ & Domestic pig & 2010 & $\mathrm{NK}^{\mathrm{a}}$ & $\mathrm{DRC}^{\mathrm{b}}$ & KX121552 & I & (30) \\
\hline TAN/12/lringa & Domestic pig & 2012 & Iringa & Tanzania & KF834193 & $\|$ & (31) \\
\hline ВOT/1/99 & Domestic pig & 1999 & NK & Botswana & AF504886 & III & $(27)$ \\
\hline $\mathrm{RSA} 1 / 99 / \mathrm{W}$ & NK & 1999 & NK & South Africa & AF449477 & IV & $(27)$ \\
\hline Tengani & Warthog & NK & Tengani & Malawi & AF301541 & V & $(32)$ \\
\hline SPEC265 & Domestic pig & 1994 & NK & Mozambique & AF270710 & $\mathrm{Vl}$ & (32) \\
\hline $\mathrm{RSA} 1 / 98$ & NK & 1998 & NK & South Africa & AF302818 & VII & $(27)$ \\
\hline MOZ/1/98 & Domestic pig & 1998 & Tete & Mozambique & AF270705 & VIII & $(27)$ \\
\hline Ug12.Kabale1 & Domestic pig & 2012 & Kabale & Uganda & KC990890 & IX & (33) \\
\hline BUR/18/Rutana & Domestic Pig & 2018 & Rutana & Burundi & MK829709 & $x$ & This study \\
\hline Kenya 1950 & Domestic pig & 1950 & NK & Kenya & AY261360 & $x$ & (34) \\
\hline TAN/Kwh12 & Warthog & 1968 & Kirawira & Tanzania & AF301546 & $x$ & $(27)$ \\
\hline KAB 94/1 & Domestic pig & 1994 & NK & Kenya & AY972163 & $x$ & $(35)$ \\
\hline $\mathrm{KIRT} / 893$ & Ticks & 1989 & Kirawira & Tanzania & AY351512 & $x$ & (5) \\
\hline TAN/16/Ngara & Domestic pig & 2016 & Ngara & Tanzania & MF437293 & $x$ & (36) \\
\hline TAN/15/Mwanza & Domestic pig & 2015 & Mwanza & Tanzania & MF437291 & $x$ & $(36)$ \\
\hline BUR/1/84 & Domestic pig & 1984 & Gitega & Burundi & AF449463 & $x$ & $(27)$ \\
\hline BUR/90/1 & Domestic pig & 1990 & Muyinga & Burundi & AF449472 & $x$ & (5) \\
\hline Ken05/Tk1 & Tick & 2005 & Kapiti plains & Kenya & NC_044945 & $x$ & (34) \\
\hline $\mathrm{KAB} / 62$ & Ticks & 1983 & Livingstone Game Park & Zambia & AY351522 & $X I$ & (5) \\
\hline $\mathrm{MZI} / 921$ & Domestic pig & 1992 & Mzinda & Malawi & AY351543 & XII & (5) \\
\hline SUM/1411 & Ticks & & Sumbu Park & Zambia & AY351542 & XIII & (5) \\
\hline $\mathrm{DRC} / 35 / 10 / 3$ & Domestic pig & 2010 & Ngaliema & DRC & KX121550 & XIV & $(30)$ \\
\hline TAN/08/Mazimbu & Domestic pig & 2008 & Mazimbu & Tanzania & GQ410765 & $X V$ & $(37)$ \\
\hline TAN/2003/1 & Domestic pig & 2003 & Arusha & Tanzania & AY494550 & $\mathrm{XVI}$ & (5) \\
\hline ZIM/92/1 & Domestic pig & 1992 & Gweru & Zimbabwe & DQ250119 & XVII & (38) \\
\hline NAM/1/95 & NK & 1995 & Windhoek & Namibia & DQ250122 & XVIII & (38) \\
\hline SPEC/251 & NK & 1996 & Ellisras & South Africa & DQ250118 & XIX & $(38)$ \\
\hline Lillie & Domestic pig & NK & NK & South Africa & DQ250109 & $X X$ & $(38)$ \\
\hline $\mathrm{RSA} 1 / 96$ & NK & 1996 & Gravelotte & South Africa & DQ250125 & $X X I$ & (38) \\
\hline SPEC/245 & NK & NK & Louis Trichardt & South Africa & DQ250117 & XXII & $(38)$ \\
\hline $\mathrm{ETH} / 5 \mathrm{a}$ & Domestic pig & 2011 & Bahir Dar & Ethiopia & KT795361 & XXIII & $(4)$ \\
\hline MOZ_11/2006 & Tick & 2006 & Gorongosa National Park & Mozambique & KY353990 & XXIV & (6) \\
\hline
\end{tabular}

${ }^{a}$ Not known.

${ }^{b}$ Democratic Republic of the Congo. 
in August 2018. The disease started in Mutwana village in the Giharo district of the Rutana region in South-Eastern Burundi (Figure 1). The number of domestic pigs that died during the outbreak was recorded from Rutana Region Livestock Office records. Tissues (lung, spleen, and liver) were collected from three domestic pigs that naturally died from the disease. Each tissue (lung, spleen, and liver) was aseptically collected into a separate tube. Samples were chilled on ice and transported to the laboratory. In the laboratory, $1 \mathrm{~g}$ from each of the tissue samples was separately placed into a sterile petri dish and chopped using a sterile scalpel blade in the presence of $10 \mathrm{~mL}$ sterile phosphatebuffered saline (PBS). Afterward, homogenized tissue samples were centrifuged at $6,000 \mathrm{~g}$ for $5 \mathrm{~min}$, and the supernatants, aliquoted into cryovials before cryopreservation at $-80^{\circ} \mathrm{C}$ until DNA extraction.

\section{DNA Extraction}

Frozen aliquots of lung, liver, and spleen homogenates were allowed to thaw, and DNA was extracted directly from 150 $\mu \mathrm{L}$ of homogenized tissue samples using a QiaAmp nucleic acid extraction kit (Qiagen, Hilden, Germany), following the manufacturer's instructions. Each extraction yielded $50 \mu \mathrm{L}$ of DNA whose quantity and purity were determined by a nanodrop spectrophotometer (Biochrom, Cambridge, England) before being stored at $-20^{\circ} \mathrm{C}$ until nucleotide amplification by polymerase chain reaction (PCR).

\section{Amplification of ASFV DNA}

The disease confirmation was carried out by PCR using ASF diagnostic primers PPA1 and PPA2 as previously described by Agüero et al. (26). Amplification for partial nucleotide sequencing of ASFV DNA was conducted using primers that target (i) the variable $3^{\prime}$-end of the $B 646 L$ gene encoding the major capsid protein p72 using primers p72D and p72U (27), (ii) a TRS located between the $I 73 R$ and $I 329 L$ genes using primers ECO1A and ECO1B (28), and (iii) the CVR of the B602L gene using the ORF9L-F and ORF9L-R primer pair $(21,29)$. The amplification conditions used in the present study were similar to those previously described (21, 26-29). All nucleotide amplifications were performed using AccuPower PCR premix (Bioneer, Daejeon, Republic of Korea) on a GeneAmp 9700 PCR system (Applied Biosystems, Foster City, CA). Afterward, the electrophoretic separation of amplicons was conducted on $1.5 \%$ agarose gel mixed with GelRed nucleic acid stain (Phenix Research Products, Candler, NC) against a $1 \mathrm{Kbp}$ molecular weight marker (Promega, Madison, WI, USA) before visualization and imaging using a Gel Doc ${ }^{\mathrm{TM}} \mathrm{EZ}$ Imager agarose gel imaging system (Bio-Rad, Hercules, CA).

\section{ASFV Partial Genome Nucleotide Sequencing}

PCR products from B646L (p72), TRS, and CVR were subjected to automated dideoxynucleotide cycle sequencing using a Big Dye Terminator Cycle sequencing kit V3.1 (Applied Biosystem, Foster City, CA) using primers: p72D, p72U, ECO1A, ECO1B, ORF9L-F, and ORF9L-R. Products from the cycle sequencing reaction were purified by ethanol precipitation and separated by capillary gel electrophoresis on an ABI 3730xl DNA analyzer (Applied Biosystems, Foster City, CA). Chromatograms for both the forward and the reverse primer reactions were checked for quality using Sequence Scanner v2.0 software (Applied Biosystems, Foster City, CA). The forward nucleotide sequence and the reverse complement nucleotide sequence from the reverse primer were subjected to pairwise alignment in Bioedit v7.2.5 (Ibis Biosciences, Carlsbad, CA) in order to obtain a single consensus nucleotide sequence delimited by the forward and reverse primers. In addition to the Burundian 2018 ASFV, the TRS between the I73R and I329L genes of the Tanzanian ASFV strains TAN/13/Arusha, TAN/16/Babati, and TAN/16/Ngara was amplified and sequenced in this study. The CVR of the B602L gene was amplified and sequenced for TAN/16/Ngara in the present study.

\section{Phylogenetic Analysis of ASFV B646L (p72), TRS, and CVR}

The nucleotide sequences of B646L (p72), TRS, and CVR from the 2018 ASFV that caused an outbreak in South-Eastern Burundi were submitted to GenBank and assigned accession

TABLE 2 | Tetramer amino acid repeat signatures within the central variable region (CVR) of the B604L gene of selected ASFV strains belonging to p72 genotype X from some East African countries.

\begin{tabular}{|c|c|c|c|c|c|c|}
\hline Strain name & $\begin{array}{c}\text { Year of } \\
\text { collection }\end{array}$ & Country of origin & Host & $\begin{array}{l}\text { CVR accession } \\
\text { number }\end{array}$ & CVR signature & Reference \\
\hline BUR/18/Rutana & 2018 & Burundi & Domestic pig & MT550685 & AAABNAABA & This study \\
\hline TAN/16/Ngara & 2016 & Tanzania & Domestic pig & MT550686 & AAABNAABA & This study \\
\hline TAN/13/Arusha & 2013 & Tanzania & Domestic pig & KF706367 & $\mathrm{BNBA}(\mathrm{BN})_{5} \mathrm{NA}$ & (23) \\
\hline Ken05/Tk3 & 2005 & Kenya & Tick & HM745290 & AAANAABBA & (39) \\
\hline TAN/13/Moshi & 2013 & Tanzania & Domestic pig & KF706364 & $\mathrm{BNBA}(\mathrm{BN})_{5} \mathrm{NA}$ & (23) \\
\hline Ken08BP/HB & 2008 & Kenya & Bushpig & JN590917 & AAABNAAAABA & Unpublished \\
\hline Bur90/1 & 1990 & Burundi & Domestic pig & AM259424 & AAABNAAAAAAAAAABA & (21) \\
\hline Bur84/2 & 1984 & Burundi & Domestic pig & AM259423 & AAABNAAAAAAAAAABA & (21) \\
\hline Bur84/1 & 1984 & Burundi & Domestic pig & AM259422 & AAABNAAAAAAAAAABA & $(21)$ \\
\hline
\end{tabular}

Key: (CAST, CVST, CTST, CASI = A), (CADT, CADI, CTDT, CAGT, CVDT = B), (NVDT, NVGT, NVDI = N), and $(C A S M=D)$. 
numbers (Tables 1, 2). The similarity search of the obtained nucleotide sequences against other ASFV sequences available at GenBank was performed using BLASTn (version 2.8.1+). The nucleotide sequence of B646L (p72) of the Burundian 2018 ASFV outbreak was aligned with other ASFV nucleotide sequences representing the 24 ASFV B646L (p72) genotypes $(6,11,15)$ using the ClustalW algorithm in MEGA X (40). ClustalW was used to perform multiple sequence alignment of nucleotide sequences of the TRS as implemented in MEGA X (40). Nucleotide sequences of the B602L (CVR) gene were translated using the ExPASy translation tool (https://web.expasy.org/translate/) and coded in order to obtain corresponding amino acid tetramer signatures

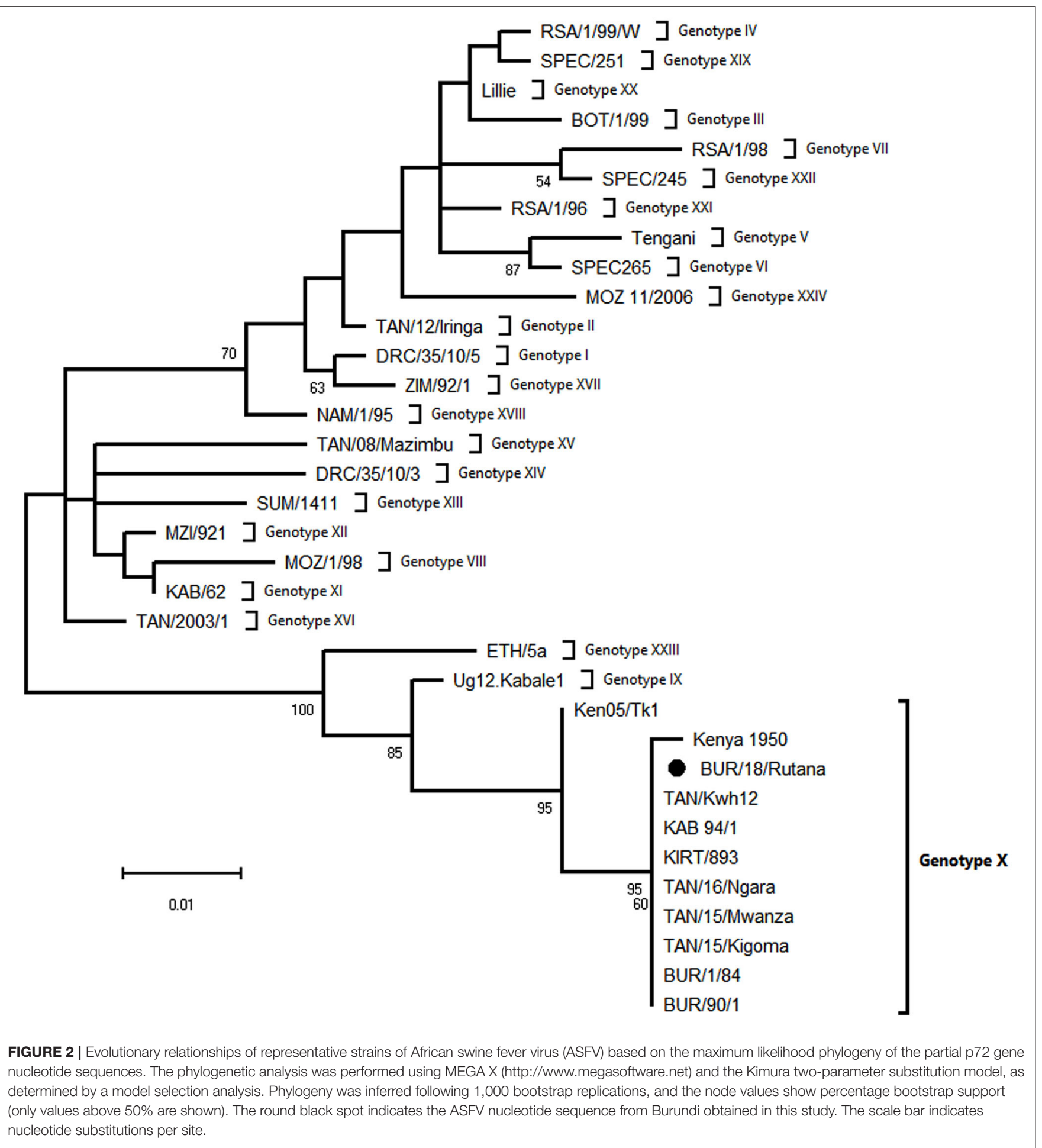




\begin{tabular}{|c|c|}
\hline BUR/18/Rutana (MK829710) & -------AATGGCTAAGCTGAACTAATATTAAGCTTTTTTTTTTCAACGAAAA \\
\hline TAN/16/Ngara (MT550689) & -----------AATGGCTAAGCTGAACTAATATTAAGCTTTTTTTTTTCAACGAAAA \\
\hline Ken05/Tk1 (NC_044945) & ------------AATGGCTAAGCTGAACTAATATTAAGCTTTTTTTT--CAACGAAAA \\
\hline KenYa 1950 (AY261360) & ATTATAGGTATATAGGAGATTATAGGGTATATGATTATAGAATAAATAAGATTATAGGAATGGCTAAGCTGAACTAATATTAAGCTTTTTTTTT-CAACGAAAA \\
\hline TAN/13/Arusha (MT550687) & ATTATAGGTATATAGGAGATTATAGGGTATATGATTATAG------------------GAATGGCTAAGCTGAACTAATATTAAGCTTTTTTTTT-CAACGAAAA \\
\hline TAN/16/Babati (MT550688) & TAATAGGIATATAGGAGATTATAGGGTATATGATTATAG------------------GAATGGCTAAGCTGAACTAATATTAAGCTTTTTTTTT-CAACGAAAA \\
\hline \multicolumn{2}{|c|}{$\begin{array}{l}\text { FIGURE } 3 \text { | Partial nucleotide sequence alignment of the intergenic region between I73R and I329L genes in ASFV isolates belonging to B646L (p72) genotype X fron } \\
\text { Eastern Africa. The nucleotides highlighted in gray, present in the reference ASFV strain, are absent in the } 2016 \text { Tanzanian ASFV, the } 2018 \text { Burundian ASFV, and the } \\
\text { ick strain described in Kenya in 2005. Other nucleotide variations between ASFV strains are highlighted in red and pink. The GenBank accession numbers of the } \\
\text { nucleotide sequences are shown in parentheses. }\end{array}$} \\
\hline
\end{tabular}

as previously described $(21,23,29)$. The evolutionary history of ASFV was inferred by the maximum likelihood method using the Kimura two-parameter model implemented in MEGA X (40). Phylogeny was inferred following 1,000 bootstrap replications.

\section{RESULTS}

\section{Outbreak Description}

The outbreak described in this study was reported in Mutwana village (Giharo district) in August 2018 (Figure 1). Afterward, ASF spread from Mutwana to neighboring villages of the Muzye, Butezi, Giharo, and Gakungu zones in the Giharo district before it was reported in villages of the Kinzanza and Gitanga zones of the Gitanga district in September 2018 (Figure 1). A total of 3,509 domestic pigs from 1,958 households died in both districts of the Rutana region, South-Eastern Burundi. The main clinical signs presented by affected domestic pigs included anorexia, dyspnea, and congestion of the skin particularly on the peripheral part of the pinna, belly, neck region, and mammary glands, followed by sudden death. Postmortem findings included hydrothorax, splenomegaly, and hemorrhages in the lung, liver, and lymph nodes, especially the hepatogastric and mesenteric lymph nodes.

\section{Confirmation of ASF Using PCR}

Each of the lung, liver, and spleen obtained from pigs that naturally died from the disease were tested for the presence of ASFV as previously described (26). All lung, liver, and spleen tissues from the three sampled domestic pigs were found to be positive for ASFV. The spleen had a high ASFV DNA concentration on a nanodrop spectrophotometer, followed by the lung and liver, at 501, 336.5, and $141.5 \mathrm{ng} / \mu \mathrm{L}$, respectively.

\section{Molecular Characterization of ASFV}

The ASFV strain from the Rutana region (South-Eastern Burundi) obtained in this study was designated as BUR/18/Rutana. BLASTn of BUR/18/Rutana B646L (p72) ASFV nucleotide sequences in GenBank showed high nucleotide identity to B646L (p72) genotype X ASFV strains previously described in Tanzania and Kenya. In order to determine the genetic relationship of BUR/18/Rutana with other ASFVs representing the 24 B646L (p72) ASFV genotypes, a phylogenetic tree was constructed with the maximum likelihood method using partial B646L (p72) nucleotide sequences. The BUR/18/Rutana ASFV strains clustered together with genotype
X strains previously described in Burundi, Tanzania, and Kenya (Figure 2).

We amplified the region located between the $I 73 \mathrm{R}$ and $I 329 \mathrm{~L}$ genes, characterized by the presence of TRS. The most similar TRS was that of TAN/16/Ngara responsible for the 2016 ASF outbreak in domestic pigs in the Ngara district of Kagera Region, South-Western Tanzania, followed by that of Ken05/Tk1 collected from a tick in Kenya in 2005 (Figure 3). We compared the Kenya 1950 isolate, which is a reference for genotype X, with BUR/18/Rutana. The ASFV strain BUR/18/Rutana lacked a $32 \mathrm{bp}$ fragment in the TRS (Figure 3), as was the case for the TAN/16/Ngara and Ken05/Tk1 strains (34). In addition, the Burundian ASFV strain described in this study had the signature AAABNAABA at the B602L (CVR) gene and showed $100 \%$ amino acid sequence identity to TAN/16/Ngara (Table 2).

\section{DISCUSSION}

ASF is endemic in Burundi, and 24,696 ASF cases have been reported in the country between January 2005 and December 2018 (13); the disease continues to economically impact on smallscale farmers. In this study, we report an outbreak of a highly fatal hemorrhagic disease of domestic pigs that occurred in 2018 in the Rutana region of Burundi. The presence of ASFV in domestic pigs was confirmed by nucleotide amplification, sequencing, and phylogenetic reconstruction of the ASFV B646L (p72) gene, the region located between the $I 73 R$ and $I 329 L$ genes characterized by the presence of TRS, and the B602L (CVR) gene. Partial sequencing of the $B 646 \mathrm{~L}$ (p72) gene is used in order to determine the ASFV genotype. However, to achieve more resolution among closely related strains, analysis of additional ASFV genomic regions is needed $(21,28)$. Regions with tandem repeat arrays within the coding or in intergenic regions identified in the ASFV genome have proven useful for discerning between closely related ASFV strains (21). Among these regions, the TRS located in the CVR within the B602L gene and the TRS located in the intergenic region between the $I 73 R$ and $I 329 L$ genes have been described as suitable to distinguish between closely related ASFV strains and to trace the source of ASF outbreaks $(21,28,41,42)$. Thus, in the present study, B646L (p72), B602L, and the TRS between the $I 73 R$ and $I 329 L$ genes were analyzed to achieve higher resolution. The results obtained from the present study confirm an ASF outbreak in the Rutana region in South-Eastern Burundi. 

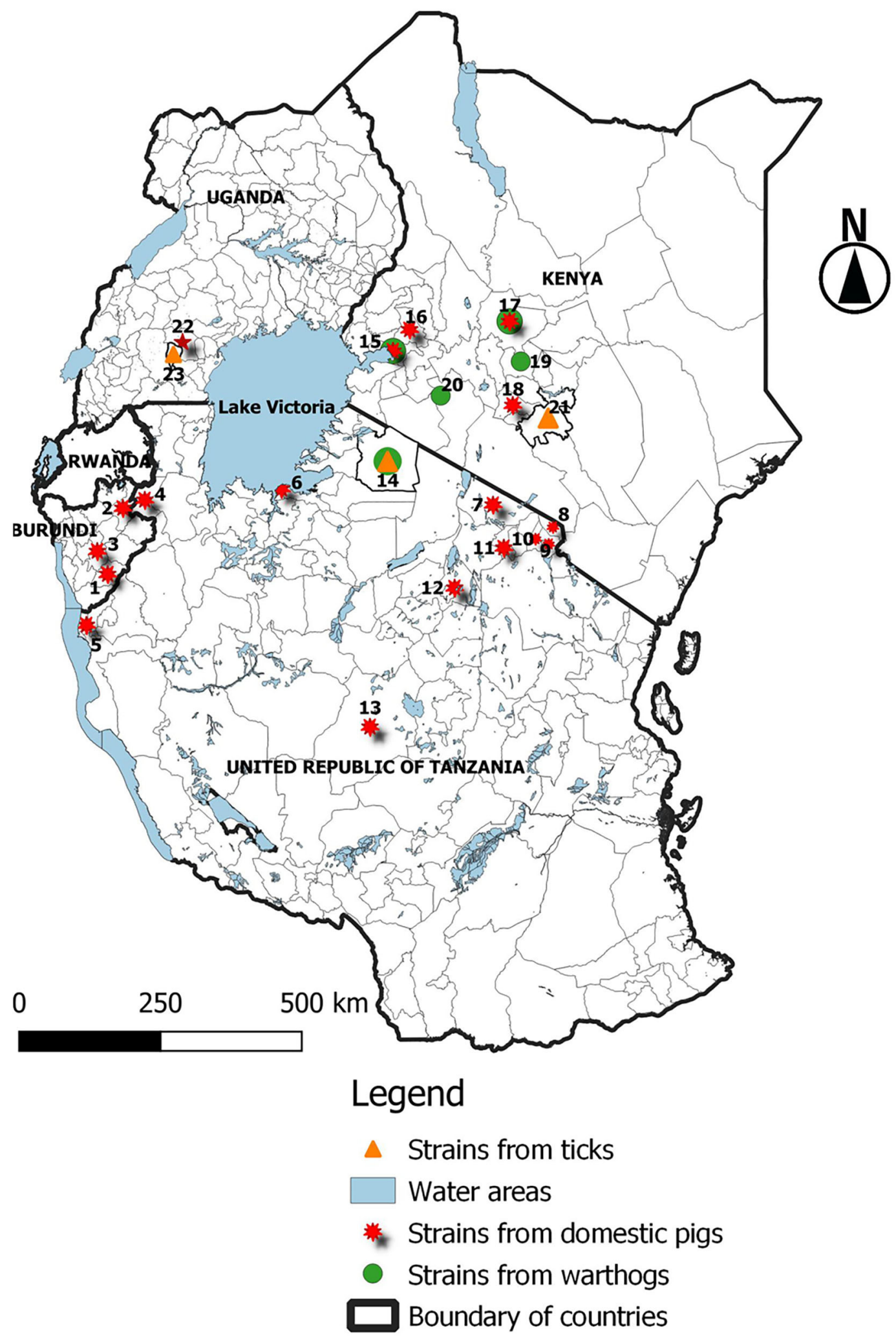

FIGURE 4 | Distribution of ASFV p72 genotype X isolates in the East African Community (EAC) between 1954 and $2018 .{ }^{1}$ Rutana 2018 [domestic pig (Dp)]; ${ }^{2}$ Muyinga 1990 (Dp); ${ }^{3}$ Gitega 1984 (Dp); ${ }^{4}$ Ngara 2016 (Dp); ${ }^{5}$ Kigoma 2004 and 2015 (Dp); ${ }^{6}$ Mwanza 2015 (Dp); ${ }^{7}$ Longido 2009 (Dp); ${ }^{8}$ Rombo 2013 (Dp); ${ }^{9}$ Moshi 2013 (Dp); ${ }^{10}$ Machame 2013 (Dp); ${ }^{11}$ Arusha 2013 (Dp); ${ }^{12}$ Babati 2016 (Dp); ${ }^{13}$ Manyoni 2015 (Dp); ${ }^{14}$ Kirawira 1968 [warthog (Wh)] and 1989 [Wh and tick (Tk)]; 15 Nyanza 2008 
FIGURE 4 | (Dp and Wh); ${ }^{16}$ Nandi 2005 (Dp); ${ }^{17}$ Nanyuki 1954 (Dp), 1959 (Dp and Wh), and 1961 (Dp); ${ }^{18}$ Kiambu 2005 (Dp); ${ }^{19}$ Kiganjo and Mweiga 1957 and 1959 (Wh); ${ }^{20}$ Rift valley 1959 (Wh); ${ }^{21}$ Machakos 2005 and 2009 (Tk); ${ }^{22}$ SSembabule 1995 (Dp); ${ }^{23}$ Lake Mburu national park 2010 (Tk). The isolates from Kenya in 1950 (Kenya 1950) and Uganda in 1964 (Ug64) are not indicated on the map, because their locations are not mentioned in the available literature.

The ASFV responsible for the 2018 outbreak in the Rutana region belonged to $B 646 L$ (p72) genotype $\mathrm{X}$ and was closely related to other genotype $\mathrm{X}$ strains previously characterized in Burundi, Tanzania, and Kenya $(28,34,41)$. Genotype X is one of the predominant ASFV p72 genotypes in countries of the East African Community (Figure 4), and it has been isolated from domestic pigs, warthogs, and Ornothodoros ticks in the region $(23,39)$. The ASFV p72 genotype $\mathrm{X}$ has been involved in previous outbreaks in Burundi in 1984 and 1990, in Gitega and Muyinga, respectively $(5,21)$. The ASFV BUR/18/Rutana lacked a $32 \mathrm{bp}$ fragment within TRS compared to the reference genotype $\mathrm{X}$ isolate, Kenya 1950 (40). Similarly, the same 32 bp fragment was absent in the ASFV TAN/16/Ngara strain responsible for the ASF outbreak in domestic pigs in South-Western Tanzania in 2016 and the ASFV Ken05/Tk1 strain recovered from a tick that was extracted from a warthog burrow in central Kenya in 2005 (40). In addition, the amino acid tetramer repeats within the CVR of the virus that caused the 2018 ASF outbreak in the Rutana region had the signature AAABNAABA and showed $100 \%$ similarity to the virus recovered from the outbreak in Ngara, South-Western Tanzania, in 2016. The amino acid identity was greater with TAN/16/Ngara than with the ASFV strains responsible for earlier outbreaks in Burundi in 1984 and 1990 (21).

The high genetic similarity of the virus described in this study to ASFV strains recovered from domestic pigs, warthogs, and Ornithodoros soft ticks vectors is in agreement with previous studies that classified the ASFV p72 genotype X as a sylvatic cycle associated genotype $(23,39,43)$. In Burundi, the Ruvubu and Kibira National Parks host warthogs (Phacochoerus aethiopicus) and bushpigs (Potamochoerus porcus) (18), which are natural reservoirs of ASFV, but the role of the sylvatic cycle in the maintenance and transmission of ASF in the country has not been investigated. Therefore, there is a lack of information on the potential existence of the ASF sylvatic cycle in Burundi, and this aspect should be investigated in wildlife protected areas of Burundi in order to understand the possibility of the virus spilling over from the sylvatic to the domestic cycle. The strain described in this study showed high genetic similarities with ASFV strains previously reported in Burundi and those circulating in the region, indicating regional distribution and circulation of this ASFV genotype. These findings are in agreement with previous studies in the region that have also reported transboundary distribution of different ASFV genotypes including genotype $\mathrm{X}$ between the Democratic Republic of the Congo (DRC) and Burundi (44) and genotype II between Malawi, Tanzania, and Zambia (45-48). In these studies, uncontrolled movements of domestic pigs and pork products have been cited as a major factor contributing to the transboundary spread of ASFV strains. Sequence analysis of the three ASFV genomic regions considered in this study showed that the most closely related strain was that responsible for the 2016 ASF outbreak in the Ngara district of Kagera region, South-Western Tanzania, indicating that the same viruses are causing outbreaks on both sides of the BurundiTanzania border. Kagera region on the Tanzanian side and the Rutana region in Burundi share borders, and uncontrolled animal movement, including that of domestic pigs, are more likely to happen between these two regions. For instance, movement of refugees together with their livestock, reported in the area (49), can contribute to the spread of animal diseases, including ASF. It has been reported that in order to reduce the economic loss due to ASF outbreaks, some farmers sell their pigs before they show clinical signs as soon as ASF is suspected. This emergency pig sell contributes to the spread of the virus in resource-poor settings, including between countries (50-52). However, considering the proximity of the Rutana region to Ruvubu National Park, where warthogs are present (20), and the reported uncontrolled movement of wild animal species between Ruvubu National Park in Burundi, Akagera National Park in Rwanda, and the Kimisi and Burigi game reserves in Tanzania (49), the virus spillover from the sylvatic to the domestic cycle cannot be excluded based on the results of this study.

This study confirms that the 2018 ASF outbreak in the Rutana region, South-Eastern Burundi, was caused by the ASFV p72 genotype $\mathrm{X}$. The virus showed high genetic similarities with ASFV strains previously described in domestic pigs, warthogs, and soft ticks in East African countries, indicating a possible common wild source and continuous circulation in domestic pigs in the region. This study contributes to the understanding of ASFV epidemiology in Burundi and in the East African Community. It will be interesting to investigate the role of the ASFV sylvatic cycle in Burundi and to perform whole genome sequencing of the ASFV strains reported in this study along with those previously described in Burundi and ASFV strains from neighboring countries to facilitate a better understanding of ASFV dynamics and epidemiology in Eastern and Southern Africa. Such perspective on the changing dynamics may provide an understanding of the global epidemiology of ASF.

\section{DATA AVAILABILITY STATEMENT}

The datasets generated for this study can be found in online repositories. The names of the repository/repositories and accession number(s) can be found in the article.

\section{AUTHOR CONTRIBUTIONS}

JH, GM, and JN designed the study. JH and LN participated in sample collection and laboratory analysis. JH, GM, and CY analyzed and interpreted data. $\mathrm{JH}$ wrote the first draft of the manuscript. JN, LN, CY, OK, DN, GM, and $\mathrm{HN}$ reviewed and edited the manuscript. All authors read and approved the 
final manuscript. All authors contributed to the article and approved the submitted version.

\section{FUNDING}

This study was funded by the Partnership for Skills in Applied Sciences, Engineering and Technology (PASET) through the Regional Scholarship and Innovation Fund (RSIF) awarded to $\mathrm{JH}$ to carry out doctoral studies at SACIDS Africa Center of Excellence for Infectious Diseases, SACIDS Foundation for One

\section{REFERENCES}

1. Montgomery ER. On a form of swine fever occurring in British East Africa (Kenya Colony). J Comp Pathol Ther. (1921) 34:15991. doi: 10.1016/S0368-1742(21)80031-4

2. Penrith $\mathrm{M}-\mathrm{L}$, Bastos $\mathrm{AD}$, Etter EMC, Beltrán-Alcrudo D. Epidemiology of African swine fever in Africa today: sylvatic cycle versus socio-economic imperatives. Transbound Emerg Dis. (2019) 66:672-86. doi: 10.1111/tbed.13117

3. Alonso C, Borca M, Dixon L, Revilla Y, Rodriguez F, Escribano JM, et al. ICTV virus taxonomy profile: Asfarviridae. J Gen Virol. (2018) 99:6134. doi: 10.1099/jgv.0.001049

4. Achenbach JE, Gallardo C, Nieto-Pelegrín E, Rivera-Arroyo B, Degefa-Negi $\mathrm{T}$, Arias $\mathrm{M}$, et al. Identification of a new genotype of African swine fever virus in domestic pigs from Ethiopia. Transbound Emerg Dis. (2017) 64:1393404. doi: 10.1111/tbed.12511

5. Lubisi BA, Bastos ADS, Dwarka RM, Vosloo W. Molecular epidemiology of African swine fever in East Africa. Arch Virol. (2005) 150:243952. doi: 10.1007/s00705-005-0602-1

6. Quembo CJ, Jori F, Vosloo W, Heath L. Genetic characterization of African swine fever virus isolates from soft ticks at the wildlife/domestic interface in Mozambique and identification of a novel genotype. Transbound Emerg Dis. (2018) 65:420-31. doi: 10.1111/tbed.12700

7. de Villiers EP, Gallardo C, Arias M, da Silva M, Upton C, Martin R, et al. Phylogenomic analysis of 11 complete African swine fever virus genome sequences. Virology. (2010) 400:128-36. doi: 10.1016/j.virol.2010.01.019

8. Penrith ML. African swine fever. Onderstepoort J Vet Res. (2009) 76:915. doi: 10.4102/ojvr.v76i1.70

9. Andraud M, Halasa T, Boklund A, Rose N. Threat to the French swine industry of African swine fever: surveillance, spread, and control perspectives. Front Vet Sci. (2019) 6:248. doi: 10.3389/fvets.2019.00248

10. Sang H, Miller G, Lokhandwala S, Sangewar N, Waghela SD, Bishop RP, et al. Progress toward development of effective and safe African swine fever virus vaccines. Front Vet Sci. (2020) 7:84. doi: 10.3389/fvets.2020.00084

11. Garigliany M, Desmecht D, Tignon M, Cassart D, Lesenfant C, Paternostre J, et al. Phylogeographic analysis of African swine fever virus, Western Europe, 2018. Emerg Infect Dis. (2019) 25:184-6. doi: 10.3201/eid2501.181535

12. Galindo I, Alonso C. African swine fever virus: a review. Viruses. (2017) 9:103. doi: 10.3390/v9050103

13. OIE. World Animal Health Information System. (2020). Available online at: http://www.oie.int/wahis_2/public/wahid.php/Countryinformation/ Reporting (accessed April 28, 2020).

14. Taylor RA, Condoleo R, Simons RRL, Gale P, Kelly LA, Snary EL. The risk of infection by African swine fever virus in European swine through boar movement and legal trade of pigs and pig meat. Front Vet Sci. (2020) 6:486. doi: 10.3389/fvets.2019.00486

15. Ge S, Li J, Fan X, Liu F, Li L, Wang Q, et al. Molecular characterization of African swine fever virus, China, 2018. Emerg Infect Dis. (2018) 24:21313. doi: $10.3201 /$ eid2411.181274

16. Li X, Tian K. African swine fever in China. Vet Rec. (2018) 183:3001. doi: $10.1136 /$ vr.k3774
Health, Sokoine University of Agriculture, Morogoro, Tanzania. The funders had no role in study design, data collection and analysis, decision to publish, or preparation of the manuscript.

\section{ACKNOWLEDGMENTS}

The authors were especially grateful to Mariam R. Makange, Mhoja Ndalahwa, Anna Rogath Masawe, Beatrice Karegeya, Caritas Iradukunda, and Ambroise Ndikumagenge for their excellent technical assistance.

17. Etter EMC, Seck I, Grosbois V, Jori F, Blanco E, Vial L, et al. Seroprevalence of African swine fever in Senegal, 2006. Emerg Infect Dis. (2011) 17:4954. doi: 10.3201/eid1701.100896

18. Boinas FS, Wilson AJ, Hutchings GH, Martins C, Dixon LJ. The persistence of African swine fever virus in field-infected Ornithodoros erraticus during the ASF endemic period in Portugal. PLoS ONE. (2011) 6:e20383. doi: 10.1371/journal.pone.0020383

19. Jori F, Vial L, Penrith ML, Pérez-Sánchez R, Etter E, Albina E, et al. Review of the sylvatic cycle of African swine fever in sub-Saharan Africa and the Indian ocean. Virus Res. (2013) 173:212-27. doi: 10.1016/j.virusres.2012.10.005

20. UICN/PACO. Parcs et réserves du Burundi: évaluation de l'efficacité de gestion des aires protégées. Ouagadougou, BF: UICN/PACO (2011). p. 112.

21. Nix RJ, Gallardo C, Hutchings G, Blanco E, Dixon LK. Molecular epidemiology of African swine fever virus studied by analysis of four variable genome regions. Arch Virol. (2006) 151:247594. doi: 10.1007/s00705-006-0794-Z

22. Costard S, Wieland B, de Glanville W, Jori F, Rowlands R, Vosloo W, et al. African swine fever: how can global spread be prevented? Philos Trans $R$ Soc Lond B Biol Sci. (2009) 364:2683-96. doi: 10.1098/rstb.2009.0098

23. Misinzo G, Kwavi DE, Sikombe CD, Makange M, Peter E, Muhairwa AP, et al. Molecular characterization of African swine fever virus from domestic pigs in northern Tanzania during an outbreak in 2013. Trop Anim Health Prod. (2014) 46:1199-207. doi: 10.1007/s11250-014-0628-z

24. Mulumba-Mfumu LK, Saegerman C, Dixon LK, Madimba KC, Kazadi E, Mukalakata NT, et al. African swine fever: update on Eastern, Central and Southern Africa. Transbound Emerg Dis. (2019) 66:146280. doi: 10.1111/tbed.13187

25. Mwiine FN, Nkamwesiga J, Ndekezi C, Ochwo S. Molecular characterization of African swine fever viruses from outbreaks in Peri-Urban Kampala, Uganda. Adv Virol. (2019) 2019:1463245. doi: 10.1155/2019/1463245

26. Agüero M, Fernández J, Romero L, Sánchez Mascaraque C, Arias M, SánchezVizcaíno JM. Highly sensitive PCR assay for routine diagnosis of African swine fever virus in clinical samples. J Clin Microbiol. (2003) 41:44314. doi: 10.1128/JCM.41.9.4431-4434.2003

27. Bastos ADS, Penrith M-L, Crucière C, Edrich JL, Hutchings G, Roger F, et al. Genotyping field strains of African swine fever virus by partial p72 gene characterisation. Arch Virol. (2003) 148:693-706. doi: 10.1007/s00705-002-0946-8

28. Gallardo C, Fernández-Pinero J, Pelayo V, Gazaev I, Markowska-Daniel I, Pridotkas G, et al. Genetic variation among African swine fever genotype II viruses, Eastern and Central Europe. Emerg Infect Dis. (2014) 20:15447. doi: 10.3201/eid2009.140554

29. Irusta PM, Borca MV, Kutish GF, Lu Z, Caler E, Carrillo C, et al. Amino acid tandem repeats within a late viral gene define the central variable region of African swine fever virus. Virology. (1996) 220:207. doi: 10.1006/viro.1996.0281

30. Mulumba-Mfumu LK, Achenbach JE, Mauldin MR, Dixon LK, Tshilenge CG, Thiry E, et al. Genetic assessment of African swine fever isolates involved in outbreaks in the Democratic Republic of Congo between 2005 and 2012 reveals co-circulation of p72 genotypes I, IX and XIV, including 19 variants. Viruses. (2017) 9:31. doi: 10.3390/v9020031 
31. Sikombe CD. Molecular characterisation and assessment of epidemiological risk factors of African swine fever virus in Iringa Region, Tanzania (Master's Thesis). Sokoine University of Agriculture, Morogoro, Tanzania (2013). p. 86.

32. Bastos ADS, Penrith M-L, Macome F, Pinto F, Thomson GR. Co-circulation of two genetically distinct viruses in an outbreak of African swine fever in Mozambique: no evidence for individual co-infection. Vet Microbiol. (2004) 103:169-82. doi: 10.1016/j.vetmic.2004.09.003

33. Atuhaire DK, Afayoa M, Ochwo S, Mwesigwa S, Okuni JB, Olaho-Mukani W, et al. Molecular characterization and phylogenetic study of African swine fever virus isolates from recent outbreaks in Uganda (2010-2013). Virol J. (2013) 10:247. doi: 10.1186/1743-422X-10-247

34. Bishop RP, Fleischauer C, de Villiers EP, Okoth EA, Arias M, Gallardo C, et al. Comparative analysis of the complete genome sequences of Kenyan African swine fever virus isolates within p72 genotypes IX and X. Virus Genes. (2015) 50:303-9. doi: 10.1007/s11262-014-1156-7

35. Phologane SB, Bastos ADS, Penrith M-L. Intra- and inter-genotypic size variation in the central variable region of the $9 \mathrm{RL}$ open reading frame of diverse African swine fever viruses. Virus Genes. (2005) 31:35760. doi: 10.1007/s11262-005-3254-z

36. Yona C. Studies on epidemiology and socio-economic impact associated with African swine fever 2015 - 2017 outbreaks in Tanzania (Master's thesis). Sokoine University of Agriculture, Morogoro, Tanzania (2017). p. 96.

37. Misinzo G, Magambo J, Masambu J, Yongolo MG, Van Doorsselaere J, Nauwynck HJ. Genetic characterization of African swine fever viruses from a 2008 outbreak in Tanzania. Transbound Emerg Dis. (2011) 58:8692. doi: 10.1111/j.1865-1682.2010.01177.x

38. Boshoff CI, Bastos ADS, Gerber LJ, Vosloo W. Genetic characterisation of African swine fever viruses from outbreaks in southern Africa (1973-1999). Vet Microbiol. (2007) 121:45-55. doi: 10.1016/j.vetmic.2006. 11.007

39. Gallardo C, Okoth E, Pelayo V, Anchuelo R, Martin E, Simon A, et al. African swine fever viruses with two different genotypes, both of which occur in domestic pigs, are associated with ticks and adult warthogs, respectively, at a single geographical site. J Gen Virol. (2011) 92:43244. doi: 10.1099/vir.0.025874-0

40. Kumar S, Stecher G, Li M, Knyaz C, Tamura K. MEGA X: molecular evolutionary genetics analysis across computing platforms. Mol Biol Evol. (2018) 35:1547-9. doi: 10.1093/molbev/msy096

41. Vilem A, Nurmoja I, Niine T, Riit T, Nieto R, Viltrop A, et al. Molecular characterization of African swine fever virus isolates in Estonia in 2014-2019. Pathogens. (2020) 9:582. doi: 10.3390/pathogens9070582

42. Wade A, Achenbach JE, Gallardo C, Settypalli TBK, Souley A, Djonwe G, et al. Genetic characterization of African swine fever virus in Cameroon, 2010-2018. J Microbiol Seoul Korea. (2019) 57:316-24. doi: 10.1007/s12275-019-8457-4

43. Gallardo C, Ademun AR, Nieto R, Nantima N, Arias M, Martín E, et al. Genotyping of African swine fever virus (ASFV) isolates associated with disease outbreaks in Uganda in 2007. Afr J Biotechnol. (2011) 10:348897. doi: $10.5897 / \mathrm{AJB} 10.1439$

44. Bisimwa PN, Ongus JR, Tiambo CK, Machuka EM, Bisimwa EB, Steinaa $\mathrm{L}$, et al. First detection of African swine fever (ASF) virus genotype $\mathrm{X}$ and serogroup 7 in symptomatic pigs in the Democratic Republic of Congo. Virol J. (2020) 17:135. doi: 10.1186/s12985-020-01398-8

45. Hakizimana JN, Kamwendo G, Chulu JLC, Kamana O, Nauwynck HJ, Misinzo G. Genetic profile of African swine fever virus responsible for the 2019 outbreak in northern Malawi. BMC Vet Res. (2020) 16:316. doi: 10.1186/s12917-020-02536-8

46. Misinzo G, Kasanga CJ, Mpelumbe-Ngeleja C, Masambu J, Kitambi A, Van Doorsselaere J. African swine fever virus, Tanzania, 2010-2012. Emerg Infect Dis. (2012) 18:2081-3. doi: 10.3201/eid1812.121083

47. Simulundu E, Chambaro HM, Sinkala Y, Kajihara M, Ogawa H, Mori A, et al. Co-circulation of multiple genotypes of African swine fever viruses among domestic pigs in Zambia (2013-2015). Transbound Emerg Dis. (2017) 65:114-22. doi: 10.1111/tbed.12635

48. Simulundu E, Sinkala Y, Chambaro HM, Chinyemba A, Banda F, Mooya LE, et al. Genetic characterisation of African swine fever virus from 2017 outbreaks in Zambia: identification of p72 genotype II variants in domestic pigs. Onderstepoort J Vet Res. (2018) 85:5. doi: 10.4102/ojvr.v85i1.1562

49. Ntirandekura JB, Matemba LE, Ngowi HA, Kimera SI, Karimuribo ED. Knowledge, perceptions and practices regarding brucellosis in pastoral communities of Kagera Region, Tanzania. Tanzan Vet J. (2018) 35:10211. doi: 10.5455/javar.2018.e285

50. Atuhaire KD, Ochwo S, Afayoa M, Norbert Mwiine F, Kokas I, Arinaitwe E, et al. Epidemiological overview of African swine fever in Uganda (2001-2012). J Vet Med. (2013) 2013:949638. doi: 10.1155/2013/949638

51. Chenais E, Sternberg-Lewerin S, Boqvist S, Emanuelson U, Aliro T, Tejler E, et al. African swine fever in Uganda: qualitative evaluation of three surveillance methods with implications for other resource-poor settings. Front Vet Sci. (2015) 2:51. doi: 10.3389/fvets.2015.00051

52. Dione MM, Akol J, Roesel K, Kungu J, Ouma EA, Wieland B, et al. Risk factors for African swine fever in smallholder pig production systems in Uganda. Transbound Emerg Dis. (2017) 64:872-82. doi: 10.1111/tbed.12452

Conflict of Interest: The authors declare that the research was conducted in the absence of any commercial or financial relationships that could be construed as a potential conflict of interest.

Copyright (๔ 2020 Hakizimana, Nyabongo, Ntirandekura, Yona, Ntakirutimana, Kamana, Nauwynck and Misinzo. This is an open-access article distributed under the terms of the Creative Commons Attribution License (CC BY). The use, distribution or reproduction in other forums is permitted, provided the original author(s) and the copyright owner(s) are credited and that the original publication in this journal is cited, in accordance with accepted academic practice. No use, distribution or reproduction is permitted which does not comply with these terms. 